\title{
Untying the knot: imagination, perception and their neural substrates
}

\section{Dan Cavedon-Taylor}

Received: 3 July 2020 / Accepted: 4 March 2021 / Published online: 26 March 2021

(C) The Author(s) 2021

\begin{abstract}
How tight is the conceptual connection between imagination and perception? A number of philosophers, from the early moderns to present-day predictive processing theorists, tie the knot as tightly as they can, claiming that states of the imagination, i.e. mental imagery, are a proper subset of perceptual experience. This paper labels such a view 'perceptualism' about the imagination and supplies new arguments against it. The arguments are based on high-level perceptual content and, distinctly, cognitive penetration. The paper also defuses a recent, influential argument for perceptualism based on the 'discovery' that visual perception and mental imagery share a significant neural substrate: circuitry in V1, the brain's primary visual cortex. Current neuropsychology is shown to be equivocal at best on this matter. While experiments conducted on healthy, neurotypical subjects indicate substantial neural overlap, there is extensive clinical evidence of dissociations between imagery and perception in the brain, most notably in the case of aphantasia.
\end{abstract}

Keywords Aphantasia - Brain imaging - Cognitive penetration - High-level content · Imagination $\cdot$ Mental imagery $\cdot$ Predictive processing $\cdot$ Primary visual cortex

\section{Introduction}

Let us call a theory of the imagination 'perceptualist' just in case it claims that states of the imagination are a species of perceptual experience. Perceptualism about the imagination says that when you close your eyes and imagine a ripe, yellow banana, you are in a visual state-you are visualising. The view lumps states of the imagination with states of veridical perceptual representation, illusory perceptual representation and hallucinatory perceptual representation; it says that states of the imagination are a proper subset of perceptual experience, just as these other states are.

Dan Cavedon-Taylor

dan.cavedon-taylor@open.ac.uk

1 Open University, Milton Keynes, UK 
As one might have guessed, by the term 'imagination' I mean the so-called sensory or objectual imagination, which I take to be necessarily constituted by mental imagery. I will have nothing to say about states of propositional imagining, e.g., imagining that Liverpool is the capital city of England, and which may or may not involve mental imagery. Since mental imagery is an essential constituent of the imagination (as the term is used here) I shall sometimes help myself to the convenience of using the terms 'imagination' and 'mental imagery' interchangeably.

Here is the plan. First, I further characterise perceptualism, outlining motivations for the view and contrasting it with non-perceptual accounts of the imagination (Sect. 2). Then, I offer new arguments against perceptualism. The arguments are based on considerations related to high-level content (Sect. 3) and, distinctly, cognitive penetration (Sect. 4). These aim to establish that there are differences between imagination and perception that are not mere differences in degree, but which are differences in representational nature. Finally, I attempt to defuse the contemporary master argument for perceptualism (Sect. 5) and which is based on the 'discovery' that perception and mental imagery share a significant neural substrate: V1, or the brain's primary visual cortex. I shall show that current neuropsychology is equivocal at best on this matter. Experimental psychology, which makes observations of neurotypical subjects, supports the existence of substantial neural overlap between perception and imagination. Yet evidence from clinical psychology, which makes observations of brain damaged patients, points to significant neural dissociations between the two, most notably in the case of aphantasia. Moreover, I'll suggest we have reason to take the latter, clinical findings more seriously than the former experimental ones. ${ }^{1}$

\section{Perceptualism}

Perceptualism says that states of the imagination are a proper subset of perceptual experience. By way of initially motivating the view, consider the following: veridical perceptual experiences correctly represent both objects and properties; illusory perceptual experiences are at one remove, correctly representing objects, but misrepresenting properties; and hallucinatory experiences are at one remove further still, misrepresenting both objects and properties. ${ }^{2}$

Now, we don't have to slide down this slope much further, if at all, to meet the imagination. The imagination is akin to hallucination in its being causally decoupled from the environment, while nonetheless having a sensory phenomenal character. Indeed, one way to be a perceptualist is to reduce hallucinations to states of the

\footnotetext{
1 Sections 3-5 are largely independent. Readers solely interested in aphantasia and issues surrounding the neural substrate of mental imagery can proceed directly to Sect. 5, following Sect. 2.

2 This assumes a representational account of perceptual experience (Dretske 1995; Tye 1995). Not everyone does, but I will for the purposes of this paper. See footnote 4 for brief discussion of how naïve realists typically understand imagination.
} 
imagination. This is precisely what Bence Nanay (2016, p.70) does when claiming that the hallmark of both is "perceptual processing that is not triggered by corresponding sensory stimulation in the relevant sense modality."3

Other perceptualists claim that imagination is on a continuum with perception more generally, rather than hallucination in particular. Here is Alex Byrne:

Visualizing a tiger is similar to seeing a tiger; auditorily imagining clashing cymbals is similar to hearing clashing cymbals, and so on. Why is that? The received view, supported by various lines of converging evidence, is that visualizing a tiger (for example) involves "visual representations"-mental representations that are proprietary to the sense of sight; likewise for auditorily imagining clashing cymbals... When one visualizes a tiger, one is in a state with a distinctively visual content, a pared-down version of the content of the state of seeing a tiger. (2007, pp. 134-135)

Byrne's use of the term 'pared-down' is telling. For perceptualists, any phenomenal difference between the imagination and perception, in terms of vivacity or what have you, is a mere difference in degree, not kind. Indeed, perceptualists like Nanay and Byrne typically downplay such differences. For instance, both take C. W. Perky's (1910) infamous experiments, in which seen figures back-projected on a dimly-lit screen were mistaken for imagined figures, as evidence that perception and imagination can be phenomenally indistinguishable (Byrne, 2007, p. 134; Nanay, 2016, p. 74).

Perceptualists needn't claim that imagination and perception are necessarily indistinguishable. That claim is fairly implausible and is not what Byrne or Nanay affirm. But this concession does not threaten the perceptualist's attempt to lump the imagination with hallucination, illusion and veridical perception as proper subsets of perceptual experience. After all, hallucinations and illusions (real ones, not the hypotheticals philosophers toy with) are often distinguishable from their veridical counterparts by virtue of having an air of non-reality to them. Yet this certainly doesn't undermine the grouping of hallucination and illusion with veridical perceptual experience. Similarly, perceptualists can admit that imaginative states sometimes wear their imaginative status on their sleeves-whatever that status might be exactly — while still being members of a fundamental psychological kind whose kind-mates include hallucination, illusion and veridical perception. ${ }^{4}$ It is thus

\footnotetext{
${ }^{3}$ Nanay is a complicated case. In earlier work (2015), Nanay's perceptualism is cast in terms of mental states. In more recent work $(2017,2018,2020)$, Nanay has switched to discussing mental imagery in brain processing terms. Nanay takes this to be a technical sense of 'mental imagery', with which he attempts to capture "what cognitive psychologists and neuroscientists mean by the term" (2017, p. 468) while nonetheless being an "extension" (2018, p.128) of the more ordinary sense, i.e. meaning "mental state.' Nanay's work on hallucination (2016) marks a transition between these two views; there, he at once defines mental imagery in processing terms (pp. 67-68) but then slides into talking about mental imagery in terms of "mental states" (p. 69), particularly in relation to the representationalism versus naïve realism debate (p. 77), which is not a debate about processing but mental states. Nanay's theory has recently been extended to olfaction (Young 2020).

${ }^{4}$ The claim that there is such a fundamental common kind is controversial. Disjunctivists like Martin (2002) Soteriou (2013) deny it. Perhaps unsurprisingly, Martin and Soteriou, as we shall see below, deny perceptualism about the imagination too. See also Allen (2015) for an insightful discussion of disjunctivism, hallucination and the imagination.
} 
important to recognise that perceptualists should not be read as claiming that no differences exist between imagination and perception. They just think that any such differences are ones of mere degree.

Who else affirms perceptualism, in addition to Nanay and Byrne? The idea that imagination is of a kind with perception appears to be what Alvin Goldman (2006, p. 47) claims when he asserts that seeing $O$ to be $F$ and imagining $O$ to be $F$ are "a shared kind of state, in this instance a visual kind of state." Perceptualism also seems implicit in Nick Wiltsher's (2016, p. 271) claim that we can use theories of perceptual content, like Peacocke's (1992) scenario and proto-propositional theory, to develop theories of the imagination's content.

All told, I suspect that allegiance to perceptualism is incredibly widespread. Anyone who thinks of imaginative states as ones that occur in the absence of appropriate stimuli, as many philosophers and psychologists do, thereby implies a crucial similarity with illusions and hallucinations. For a state whose nature it is to occur in this manner is one that is pictured as partaking in the kind of mismatch between mind and world characteristic of these non-veridical states. Indeed, consider the following remarks in the Stanford Encyclopedia of Philosophy's entry 'Imagination' (Liao \& Gendler, 2019): “To have a (merely) mental image is to have a perception-like experience triggered by something other than the appropriate external stimulus." For it to be correct to characterise states of the imagination in relation to 'appropriate' external stimuli, even if by their absence, one must be thinking about the imagination in broadly perceptual terms (indeed, compare the above quote from Nanay, 2016, p. 70).

Furthermore, it is clear when one looks back over the history of philosophy that perceptualism has enjoyed considerable popularity. The view is particularly evident in early modern writing about the imagination. Hobbes (1651/1991) analyses hallucinations ('visions'), along with memories and dreams, as imaginings, much like Nanay. And of course there is Hume (1739/2000), who despite claiming that imagination and perception differ in "force and liveliness" (1.1.1.1), ultimately considers them to belong to the same psychological kind:

That idea of red, which we form in the dark, and that impression which strikes our eyes in sun-shine, differ only in degree, not in nature. (1.1.1.5)

Indeed, one might reasonably call the perceptualist a 'Humean' about the imagination (Siegel \& Silins, 2015, p. 791). More recently, predictive processing theorists have endorsed perceptualism too. For instance, Andy Clark (2014, p. 39) claims that there is a "deep unity between perceiving and imagining" and that to be a perceiver is to deploy, passively, the same internal states that are deployed, actively, during will-driven imagining. The idea of an imagination/perception knot is an enduring and widely affirmed one. 
Now, consider that one way to drive a wedge between perception and imagination, and thereby deny perceptualism, would be to claim that perceptual experience is distinctive in that it presents its contents as in fact thus and so, and that perceptual appearances are therefore appearances of actuality. The contrast with imagination might be that it presents its contents either as ways things are not, but could be; or else, following Sartre (1940/2010, p. 14), as absent or non-existent, as "not being." (see also Kriegel, 2015) This would be to drive a wedge between imagination and perception at the level of attitude, since it is to grant that the two may share contents.

In contrast to this Sartrean view, consider the following remarks, again from Byrne, flying the flag for perceptualism:

[I]f sensuous imagination involves the appearance of anything, it's the appearance of actuality, not possibility. What "appears to be so", when one imagines a purple polar bear, is that purple polar bears exist, not (merely) that they could have existed. (Ibid., p. 134)

This is a bold claim, and I take it that not all perceptualists would necessarily agree. So we should perhaps say that agreeing with Byrne here is sufficient for being a perceptualist, but not necessary. In claiming that states of the imagination are a kind, or subset, of perceptual experience, perceptualists may be affirming no more than that states of the imagination are (1) intentional ones with (2) a sensory phenomenal character that (3) rationally compel belief in a non-inferential manner. That is, they may leave open whether these beliefs concern actuality or non-actual possibility. This means that perceptualism may be an exceptionally broad church. Yet this is to be expected, since much depends on one's initial take on perceptual experience. For instance, if we can see things to be absent (Farennikova, 2013), then Sartre's claim that imagination represents its contents as absent will fail to drive a wedge between the two and simply reinforce similarity.

What this all means is that the waters surrounding perceptualism are somewhat murky. Still, lest one think that perceptualism is too ill-defined for it to be distinguished from any other view, consider the so-called Dependency Thesis.

The Dependency Thesis claims that states of the imagination represent perceptual experiences rather than being among perceptual experience's subsets. The difference between these claims might seem only slight, but it is in fact substantial. After all, there is typically all the difference in the world between a representation of a $K$ and a $K$ itself. A painting of a one hundred-dollar bill is not legal tender, no matter how realistic, and a charcoal sketch of a kitten is itself neither feline nor fluffy.

Here is how M. G. F. Martin puts the Dependency Thesis:

To imagine sensorily a $\Phi$ is to imagine experiencing a $\Phi \ldots$ On this view, one kind of phenomenally conscious state, an event of imagining, takes as its object another type of conscious state of mind, a sensory experience. (2002, p. 404; see also Peacocke, 1985 and Soteriou, 2013)

This view claims that one cannot imagine objects directly. Rather, one imagines perceptual experiences of objects. This, Martin claims, is reflected in imagery's 
including a point of view as a part of its content and from which the imagination takes place, e.g., from above, below, etc. (p. 407). Whereas Sartrean accounts disagree with perceptualists about attitudinal features of the sensory imagination, defenders of the Dependency Thesis disagree with perceptualists about the contents of sensory imaginings. The Dependency Thesis claims that the contents of such imaginings are perceptual experiences while the contents of perceptual experiences are objects and their properties. As a result, defenders of the Dependency Thesis give a contrasting account of how perception and imagination aim at truth, claiming that perceptual experiences aim to be faithful to the nature of external objects while the imagination aims to be faithful to possible perceptual experiences (Soteriou, 2013, ch.7). ${ }^{5}$

A third way to deny perceptualism is to place states of the imagination firmly on the side of the cognitive. As John Zeimbekis (2015, p. 298) points out, this is the view commonly assumed in the so-called imagery debate (see Pylyshyn, 1999, p. 347). Why would one hold such a view? Suppose one agrees with so-called stimulus-based or stimulus-controlled accounts of the perceptual that perceptual experiences necessarily function to represent particular individuals in the here and now. On this criterion, imagination will come out as non-perceptual. As Ben Phillips (2019, p. 319) explains: "In contrast to hallucinations, voluntary images do not even function so as to represent the environment in a stimulus-controlled manner." (See also Beck, 2018, p. 319) The crucial point is that although perceptualism may come in a number of flavours, it can be clearly distinguished from at least three views that are, or at least entail, non-perceptual analyses of the sensory imagination: (1) Sartrean accounts of the imagination, (2) the Dependency Thesis ${ }^{6}$ and (3) stimulusbased accounts of the perceptual.

Having characterised the key commitments of perceptualism and distinguished it from rival views, I shall now offer two new arguments against it (Sects. 3 and 4). Following that, I will defuse the contemporary master argument for perceptualism; namely, that mental imagery and perception share a neural substrate in the form of the early visual cortex (Sect. 5).

\footnotetext{
${ }^{5}$ Two points are worth emphasising when it comes to understanding the relationship between perceptualism and the Dependency Thesis. First, strictly speaking, the Dependency Thesis is compatible with the claim that imagination is a type of perceptual experience. (A state of kind $K$ may be represented by a state of kind $K$.) But a more natural way to understand the view, and indeed how it is pictured by Byrne (2007, n.18), is as claiming that imagination and perception are members of fundamentally distinct psychological kinds. Nanay (2015), in offering several arguments against the Dependency Thesis, also sees it as a rival to perceptualism.

Second, when interpreting past thinkers, like Hobbes and Hume, one should be careful to bear in mind the distinction between perceptualism and the Dependency Thesis. Indeed, as Fabian Dorsch (2016, pp. 41-44) argues, it does not take much tinkering with Hume's view to transform it from the former into the latter. My own view is that it may be more accurate to say that Hume unwittingly equivocated between perceptualism and the Dependency Thesis.

${ }^{6}$ My considered view is that the Dependency Thesis is just as problematic as perceptualism (see Cavedon-Taylor forthcoming, where I call the Dependency Thesis 'weak perceptualism'), but in this paper I focus solely on advancing the case against perceptualism. Readers may correctly surmise from Sect. 5 that I am sympathetic to stimulus-based views of the perceptual.
} 


\section{Perceptualism and high-level content}

Take first the debate over whether perceptual experience has high-level content. The issue is whether perceptual experience represents objects as having only basic, low-level properties, e.g., color, shape, motion, spatial orientation, etc. or whether it can also represent objects as having so-called high-level properties, e.g., natural kind properties, causal properties, psychological properties, action properties, etc.

Suppose I look into my garden and see a bird land on the fence and then quickly take flight when it spies the neighbour's cat approach through the grass. What information do I get here from vision alone, prior to forming any beliefs about what I see? High-level views might say: I see there to be a pigeon on my fence, or the cat's causing the pigeon to flee, or the cat's having the intention to pounce, and so on. Low level views might say: I see there to be a grey object located on a rectangular, brown object with an orange object moving towards it, etc. On that view, the properties, 'being a pigeon', 'being a cat', 'being a fence panel', 'causing', and 'intending' are represented post-perceptually, if not in belief proper, then in some other post-perceptual state (Reiland, 2014).

The issue has generated substantial debate. If low-level views are right, then the representational capacity of perception is greatly attenuated, compared to belief. (Belief can represent all manner of high-level properties, having almost no restrictions here.) If high-level views are right, then the gulf is not so wide. Moreover, the truth of high-level views opens up space for fully perceptual, a posteriori analyses of our knowledge of, e.g., other minds, moral rightness, etc. If low-level views are correct, then the prospects for such views is dim.

As a matter of sociological fact, high-level views are more widely affirmed than low-level ones. (A small sample: Bayne, 2009; Block, 2014; Brogaard, 2016; Fish, 2013; Matey, 2014; Nanay, 2011; Siegel, 2006; Stokes, 2018a.) But lowlevel views have several capable defenders (Byrne, 2016; Price, 2009; Tye, 1995). Moreover, the low-level view has, I think, been the more central view historically. Although high-level views currently dominate, the matter shouldn't be considered cut and dried.

So we have here a 'live' debate. Yet when we frame the issue in terms of whether states of the imagination have high-level content, the issue seems substantially less interesting. For the claim that one can literally see high-level properties, like an object's being a cat or being about to pounce, is potentially problematic in ways that the claim one can visualise an object to have such properties is intuitively not (see also Gregory, 2013, pp. 84-5). Indeed, here is Byrne (2007) affirming, without argument, that the imagination has high-level content:

The content of sensuous imagination is not restricted to simple arrangements of shapes, colors, sounds, and so on: that a small red ball is on top of a large blue cube, for instance. We can also sensuously imagine that King's College is on fire, that a tiger is stalking the Queen, that Nixon is inanimate, and so on. (p. 136) 
In fact, Byrne seems happy to populate states of the imagination with high-level content of a fairly unrestricted sort, making imagination exceptionally close to belief in its representational powers. He continues:

$[\mathrm{O}]$ ne may imagine the piano being made of ice, being the offspring of $\mathrm{Mr}$. and Mrs. Truman, turning into a butterfly and flying up the stairs, or whatever. (Ibid.)

I will grant, for the sake of argument, Byrne's assumption that the imagination has high-level content. ${ }^{7}$ My strategy for arguing against perceptualism will be on the basis of some aspects of the high-level content debate itself.

\section{The argument from high-level content}

1. If perceptualism is true, then putative grounds for denying that perceptual experience has high-level content are putative grounds for denying that states of the imagination have high-level content.

2. Putative grounds for denying that perceptual experience has high-level content are not putative grounds for denying that states of the imagination have high-level content.

3. Perceptualism is not true.

I take 1 to be entailed by perceptualism. If states of the imagination are a proper subset of perceptual experience, then challenges facing a high-level view of perceptual content will, ipso facto, be challenges for a high-level view of the imagination's content. Whether those challenges are only prima facie or are instead sufficient grounds for rejecting the high-level view of perception won't concern me. (Hence I call them only putative grounds.) Premise 2 says that challenges to perception's having high-level content have no application to imagination's having high-level content. If true, this seems evidence of a substantial asymmetry between perception and imagination, one that does not constitute a mere difference in degree, but a difference in kind; specifically, it points to a difference in representational natures. The conclusion is that perceptualism is false: states of the imagination, mental imagery in particular, are not a subset of perceptual experience; the two are not on a substantial continuum with one another nor members of the same fundamental psychological kind (though they may of course share many properties in common). In sum, I argue below that challenges to perception's having high-level content have no relevance as to whether the imagination has high-level content, suggesting that the two are quite different kinds of psychological state.

So what are some putative grounds for denying that perceptual experience has high-level content and that fail to apply to the imagination? Where, that is, is the evidence for 2 ?

\footnotetext{
7 Peter Kung (2010, p. 625) outlines a framework for thinking about the imagination's content on which some of its putative high-level content could be construed as in fact belonging to stipulation.
} 


\subsection{Illusion}

First, one key reason for resisting the claim that perception has high-level content is that this entails there are perceptual illusions of high-level properties, something many have found unpalatable. Here is Byrne yet again, this time supporting a lowlevel view of perceptual content on such grounds:

Visual illusions, as the object of study in the visual sciences, concern properties like shape, motion, colour, shading, orientation and the like, not properties like being tired, belonging to Smith or being a lemon. There is thus no immediate reason to take (visual) perceptual content to include the proposition that $o$ is a lemon, and the like. $(2009, \text { p. 449) })^{8}$

A related way of pressing the point is to claim that a visual experience that correctly represents all of an object's low-level properties is, necessarily, a veridical visual experience (Logue, 2013, pp. 5-6 though they are ultimately unpersuaded). But high-level views deny this. They leave open the possibility that a visual experience which is veridical in terms of its low-level properties might nonetheless be illusory if, e.g., a high-level property is misrepresented. This seems how a high-level theorist must think of matters when a mature perceiver sees, e.g., a realistic plastic banana in standard viewing conditions. In such a situation, the perceiver's visual experience is likely to correctly represent all of the object's low-level properties, i.e. the colours and shapes, yet will likely misrepresent the object as having a natural kind property, i.e. being a banana. This result seems troubling for the high-level view. Intuitively, the situation described above isn't illusory, at least not in a strictly perceptual sense. (It is more tempting to think that any error on the perceiver's part will be in belief alone, i.e. the perceiver will mistakenly believe that the object before them is a banana while their visual experience is error-free.) However one chooses to think of the problem, the objection is that high-level views stretch our concept of 'perceptual illusion' beyond its intuitive breaking points.

Yet this objection has no analogue in the case of mental imagery's potentially having high-level content. The objection is founded on the idea that perceptual experiences are faulty when they fail to match the world, that there's something defective, epistemically, about illusions and hallucinations as such. But this is not necessarily the case when it comes to the imagination. For instance, at home on a Sunday afternoon in winter, I may spontaneously visualise myself as being, at that very moment, on a sunny beach abroad. This situation, so described, is not epistemically problematic in the way that a sudden hallucination of being on a beach, or an illusory experience of the red carpet as golden and sandy, clearly is. In the latter two situations, something is wrong with me, and the precise respect is perceptually (perhaps also cognitively). But it does not follow that there is anything wrong with me (perceptually, cognitively or otherwise) in suddenly visualising myself on a hot

\footnotetext{
${ }^{8}$ I challenge Byrne's claim that there are no perceptual illusions of high-level properties in CavedonTaylor (2021). I believe that the rubber-hand illusion, an object of study of perceptual psychology, supplies evidence to the contrary.
} 
sunny beach when the temperature is, in fact, in the minuses and the sky overcast. Thus, the norms governing epistemic (and perhaps broader psychological) appropriateness differ quite radically across perception and imagination.

Crucially, even when imagery does aim to match one's environment, a mismatch between properties imaginatively represented and properties actually instantiated is not classified as an illusion. This is not the result that one should get, if perceptualism is true. For instance, suppose you are driving at night in foggy conditions along a narrow road. Thankfully, no other cars are out. Still, the route is precarious. Suddenly, a car appears on the road. At least, you assume it to be one; all you can visually discern are two headlights. To work out whether there is space for the cars to pass on the narrow lane, you must make an educated guess as to the shape of the other car, given the position of the headlights. But you need to do so in such a way that can directly guide your action. Solution: you imaginatively project, out into the pitch-black, the outline shape of a car that strikes you as being the correct size. (Whether this is a matter of representing only low-level properties, i.e. those corresponding to the outline shape of the car, or is also or instead a matter of representing high-level properties, i.e. the shape to be that of a car part, doesn't matter.)

Suppose, however, that you get the proportions disastrously wrong (and so crash). Then, the image projected was in error. The error is in terms of the properties your mental imagery represented as instantiated in the external world. If imaginative states are of a kind with perceptual states, then this would be a case of illusion, or at least something very close to it. Yet one would not speak here of a visual illusion or of a mis-seeing of the car's shape. (The problem was precisely that you couldn't visually experience these properties!) Thus, supposing that there are no perceptual illusions of high-level properties, this fact may threaten high-level views of perceptual content, but not high-level views of the imagination's content (no more, at least, than the idea that belief can represent such properties). When imagery misrepresents properties in the world, as when belief misrepresents such properties, 'illusion' is not the word to begin with. Thus, populating the imagination with high-level content does not, while populating perception with such content does, have relevance for the scope of perceptual illusions. This shows a significant difference in the representational nature of perceptual experience and mental imagery.

\subsection{Doppelgangers}

Another key reason for resisting the claim that perceptual experience has high-level content, but which has no analogue in the case of mental imagery, concerns perceptual doppelgangers. This argument can be pressed a number of ways (Bayne, 2009 discusses several variants). A simple version is presented by Michael Tye:

It seems plausible to suppose that the property of being a tiger is not itself a feature represented [perceptually]. Our sensory states do not track this feature. There might conceivably be creatures other than tigers that look to us phenomenally just like tigers. (1995, p.141) 
Tye's thought is that high-level properties, natural kinds in particular, are not represented by perception since our perceptual systems are not sensitive to their instantiations, as they are the instantiations of low-level properties. Our visual systems are "tuned" (p. 142) to the comings and goings of colour, shape, motion, etc. but not the genetic essences constitutive of natural kinds; visual phenomenology, in the normal course of things, changes in the face of variations to the former but not the latter. Indeed, it seems that one's visual phenomenology would fail to differ between a situation in which tigers were before one's eyes and a situation in which twigers were instead present. (Twigers, we may suppose, are creatures that happen to share all low-level properties with tigers while being a distinct species.) If this is right, then objects that are look-alikes in terms of low-level properties should be considered look-alikes simpliciter, leaving no room for high-level properties to figure in perceptual content. Again, however, this worry has no analogue in the case of mental imagery that would prevent such states from representing high-level properties. I take this to be further evidence of a representational difference between the two.

Here's why the worry doesn't carry over to the imagination. In the case of perception, high-level properties are either represented in the same bottom-up, stimulus-driven way that low-level properties like colour, shape, motion, etc. are, or (as is more likely) as a matter of cognitive penetration, i.e. a top-down effect of standing beliefs, desires, expectations, etc. on perception (more on that later). In either case, however, perception comes to represent high-level properties in an involuntary manner. Although cognitive penetration involves acquired cognitive contents altering perceptual contents, such effects on perception are largely automatic, involving an unwilled 'leaking' of such contents into perception. ${ }^{9}$

With states of the imagination, things are different. When Tye complains that the visual system is insufficiently 'tuned' to the genetic essence constitutive of natural kinds in order to represent such properties, this is not a problem in the case of the imagination. For, regardless of whether the imagination sometimes acquires content from causal interactions with the environment in the bottom-up way that perception typically does, there is another manner by which the imagination can acquire content, and which is unavailable to perception, at least in the case of representing natural kinds: by being responsive to one's intention to represent such-and-such a natural kind. For instance, I can imagine two suitably-striped creatures side-by-side, represent the creature on the left to be a tiger, the one on the right to be a twiger, and then reverse this as I please. Similarly, I can imagine two glasses of clear liquid next to one another, and represent one to be water, composed of $\mathrm{H}_{2} \mathrm{O}$, and the other to be twater, composed of XYZ; I can again freely reverse this assignation as I choose, or refrain from doing so. This might be thought to involve an accompanying propositional imagining acting on the image content, a form of imagining I have claimed can be put aside. However, given that the relevant propositional imagining would itself acquire content from a suitable "content-conveying intention" (Noordhoff, 2002, p. 430), it is not clear why propositional imagining must be appealed to here and why intention shouldn't be pictured as acting directly on imagery content.

\footnotetext{
${ }^{9}$ An exception might be when mental imagery is voluntarily projected into perception, as in the driving example, though such projection can also occur involuntarily.
} 
Thus, the problem of doppelgangers, of perception's being unable to discriminate between objects that are members of distinct natural kinds that are nonetheless identical in terms of low-level properties, has no analogue in the case of the imagination. Tye's worry arises only insofar as perceptually representing an object to fall under a natural kind is a matter of discriminating that natural kind. By contrast, as the above example illustrates, representing an object to fall under a natural kind imaginatively is (at least sometimes) a matter of intention-based designation, not discernment, of that natural kind, preventing Tye's worry from getting a foothold. ${ }^{10}$

Now, the idea that imagination bears a necessary connection to the will that perception does not is a common way to distinguish the two. The strategy is associated with both Sartre (1940/2010) and Wittgenstein (1948/1980) and continues to be defended today (see Kind, 2020, Sect. 3 for discussion). Imagining, so it goes, is an activity, something we do; we conjure images when we imagine. Perception, by contrast, is said to be something that merely happens to us and in which we are passive, receiving input from the world.

Perhaps unsurprisingly, perceptualists push back. They point out the sometimespassive nature of the imagination, appealing to examples of unbidden imagery, memory flashbacks and 'earworms' (Nanay, 2016, p. 66). This line of argument can be bolstered further by focussing on perceptual experiences that bear a necessary connection to the will and are not particularly passive. Consider, e.g., visually switching aspect on the Necker cube; listening out for a noise; sniffing to tell if that stink has gone yet; and the exploratory actions that are partially constitutive of haptic/exploratory touch. These perceptual activities give rise to perceptual experiences that are will-driven. It thus seems that we can upend entirely the supposed active/passive contrast said to hold between imagination and perception, and which I appealed to above in order to argue that Tye's worry about perception's having highlevel content has no application to the imagination.

But we should be careful here to distinguish at least three separate issues: the extent to which perceptions and imaginations can be instantiated via the will, extinguished via the will and have their contents controlled via the will. In discussion of the problem of doppelgangers, I have appealed only to the last of these, and not even in full generality, suggesting that with imagination we can represent natural (and perhaps artefactual) kinds by fiat, something we seem unable to do in the case of perception. This is entirely compatible with there being other respects in which there is no great difference between how imagination and perception relate to the will. For instance, the fact that some imaginative states, like earworms, are involuntarily instantiated and that some perceptual experiences, like tactual ones, are voluntarily instantiated, does not threaten the precise respect, outlined above, in which there is this asymmetry between imagination and perception: if we can represent high-level

\footnotetext{
${ }^{10}$ Compare Kathleen Stock (ms. p. 16), coming at the same issue from a slightly different angle: "There is apparently no analogous gap between, as one might put it, the surface appearances of the image-what it seems to the thinker to be of-and what, she has reason to believe, it is really of. That is, there is apparently no possibility that one's current 'image array', as it were, is simultaneously caused by some unexpected object or another entity." Some of the details of this paper are discussed in Wiltsher (2016).
} 
properties, then we can freely do so in the case of the imagination, but not perception. ${ }^{11}$ Crucially, this difference might seem only slight, were we not considering the matter against the background of the high-level contents debate. For the difference exposes high-level views of perception, but not high-level views of the imagination, to the problem of doppelgangers. Crucially, this thereby illustrates a difference in the representational nature of the imagination and perception, suggesting that we are dealing with a difference in kind and not degree.

\section{Perceptualism and cognitive penetration}

Reflecting on the high-level content debate is not the only way that we can drive a wedge between imagination and perceptual experience. We can also do so via reflecting on the question of whether perceptual experience is cognitively penetrable. This is the matter of whether non-perceptual states like belief, desire, etc. ever produce a direct affect upon perceptual content. Those who claim that perceptual experience is cognitively penetrable claim that it can. Those who deny the cognitive penetrability thesis claim that the effect of cognitive states on perception is either pre-perceptual, determining, e.g., the spatial allocation of perceptual attention, or else is post-perceptual, determining, e.g., what beliefs one is disposed to form on the basis of perceptual experience (Pylyshyn, 1999).

By way of illustration, consider the following: in experimental conditions, subjects who were led to believe that samples of meat originated from factory-farmed animals rated them as tasting saltier than did subjects who were led to believe that identical samples originated from humanely-farmed animals (Anderson \& Barrett, 2016). Question: in the first group, did their belief that the meat samples were from factory farmed animals literally make the meat taste saltier than it would have otherwise? Those who affirm the cognitive penetrability thesis reply 'yes', those who deny it claim 'no'. The naysayers will reply that the belief about the meat's origin either altered how those in the first group allocated their gustatory attention, e.g., causing them to selectively pick up on properties that they wouldn't have otherwise, or else the belief induced by the experimenters disposed members of the group to judge the samples particularly salty, with gustatory experience itself uniform between the two groups.

Like the question of whether perception has high-level content, the question of perception's cognitive penetrability is controversial. Many experimental studies advanced as evidence of cognitive penetration seem poorly designed, either suffering failures of replicability or else having been found vulnerable to interference or task-demand effects (Firestone \& Scholl, 2016; Machery, 2015). Crucially, introspective evidence is of little help to adjudicate matters here. Introspection lacks the keenness to distinguish cognition's affecting either (1) the pre-perceptual allocation of attention; (2) perceptual content itself (i.e. cognitive penetration); (3) what

\footnotetext{
${ }^{11}$ Compare Tim Bayne (2009, p. 395): "It does not matter what one believes about an object; it still looks like a pipe, a stethoscope, or a cigarette lighter.".
} 
post-perceptual judgements one has formed; or (4) some combination of all three. Matters are not helped by the fact that (1)-(3) occur within split-seconds of each other.

As with the question of high-level content, when we switch to framing the question of cognitive penetration in terms of whether the imagination is cognitively penetrable, the issue again seems much less controversial. Although there may be some cases when imagery is produced in a stimulus-driven way, mental imagery frequently takes as its informational input the contents of our cognitive states. In general, what we believe about an $F$ will obviously affect how we imagine an $F$ to be. In imagining a red apple, mechanisms of imagery generation will have to draw on content from standing beliefs, memories, etc. about red apples. Ditto for imagining giraffes, a desert landscape, the Eiffel Tower, etc.

With these remarks in mind, the remainder of this section will be dedicated to motivating and defending the following argument against perceptualism.

\section{The argument from cognitive penetration:}

4. If perceptualism is true, then the cognitive penetrability of the imagination is relevant for the question of perception's cognitive penetrability.

5. The cognitive penetrability of the imagination is not relevant for the question of perception's cognitive penetrability.

6. Perceptualism is not true.

As before, I take 4 to be entailed by perceptualism. If the imagination, mental imagery in particular, is a perceptual state, and if states of the imagination are cognitively penetrable, then this fact must be relevant for the question of whether perception is cognitively penetrable. Premise 5 denies the consequent of that conditional: the fact that imagination is cognitively penetrable is neither here nor there when it comes to assessing whether perceptual experience is cognitively penetrable, a matter on which I remain neutral throughout. Again, the conclusion, that perceptualism is false, follows swiftly. If the penetrability of imagination has no bearing on whether perception is cognitively penetrable, then perception and imagination must be members of quite different kinds of psychological state. As with the previous argument, the premise requiring support is 5. I shall attempt to do so via reflecting on both the terms of the penetrability debate and some of the alleged consequences of cognitive penetration.

\subsection{The terms of the penetrability debate}

Whether or not perception is cognitively penetrable, we have good reason to think that the imagination is. With this in mind, it might be tempting for friends of cognitive penetration to leverage perceptualism about the imagination to support their case, citing mental imagery as a counterexample to perception's impenetrability. As it happens, a situation like this has played out in both the philosophical and psychological literatures. Philosophy: Jesse Prinz (2006, p. 31) claims that mental imagery 
represents the "most obvious case" of cognition penetrating perception, since it involves cognitive states being "actively used to construct perceptual representations." Psychology: in response to Firestone and Scholl's (2016) critique of experimental results said to support cognitive penetrability, Howe and Carter (2016, p. 38) object with essentially the same point; perception is cognitively penetrable, they claim, since mental imagery is "obviously" cognitively penetrable.

What should we make of this inference from the cognitive penetrability of imagination to the cognitive penetrability of perception? Two objections are as follows, reflection on which support premise 5 of the above argument.

First, inferring perception's penetrability from imagination's penetrability would significantly trivialise the question of the penetrability of perception. The thesis that perception is cognitively penetrable is a highly divisive matter, from both philosophical and experimental perspectives. It is implausible that it should be resolved with a mere stroke of the pen. Yet this is how matters would stand if perceptualism were true, and states of the imagination were correctly classified as perceptual in nature. Thus, consider the question, "Is perception cognitively penetrable?" Prinz and Howe and Carter are right to claim that there is an obvious answer if states of the imagination count as perceptual states: perceptual experience counts as cognitively penetrable by virtue of the imagination being cognitively penetrable. But this very fact of 'obviousness' should alert us to the implausibility of characterising imagery as a perceptual state to begin with. Vigorous debate in both philosophy and psychology surrounding the question of perception's penetrability is evidence that the question lacks an obvious answer, and that mental imagery's penetrability by cognition is neither here nor there as far as perception's penetrability is concerned.

Second, inferring the penetrability of perception from the penetrability of imagery is to fail to engage with a key issue regarding the cognitive penetrability thesis. Consider how one of the chief sceptics about cognitive penetrability, Zenon Pylyshyn, and who is responsible for coining the term, frames the thesis. Pylyshyn is clear that by defending perception's impenetrability his thesis is not that no perceptual state is cognitively impenetrable, only that some are; namely, those belonging to early vision, a process which generates states representing basic sensory properties, e.g., edges, volumes and so-called 2.5-D depth relations. Consider:

The early vision system is encapsulated from cognition, or to use the terms we prefer, it is cognitively impenetrable. Since vision as a whole is cognitively penetrable, this leaves open the question of where the cognitive penetration occurs. (1999, p. 344)

Other sceptics about cognitive penetrability follow suit in limiting their thesis to early vision (Raftopoulos, 2009). This is important. It means that if the imagination is cognitively penetrable, then that can have no impact on the cognitive penetrability debate, classically understood. Mental imagery, even if correctly classified as a perceptual state, would not count as an output of early vision.

So, we have support here for premise 5: the cognitive penetrability of the imagination has no bearing on the question of the cognitive penetrability of perception since there is no quick route to defending the penetrability of perception on the basis of the penetrability of the imagination. Yet the cognitive penetrability of the 
imagination should have at least some bearing on the question of the cognitive penetrability of perception, if perceptualism were true, and states of the imagination were a subset of perceptual experience.

\subsection{Consequentialism about cognitive penetration}

Cognitive penetration is standardly characterised as a causal influence that cognitive states have on perceptual ones. Further matters remain to be settled, since not all causal effects of cognition on perception would seem to count. Let us define two opposing camps.

First, let us call a semanticist about cognitive penetration someone who, following Pylyshyn (1999) and Fiona Macpherson (2012), holds that the changes to perceptual content that result from cognition must be semantically coherent ones. Cognitive content must alter perceptual content in a rationally comprehensible way. Adapting an example of Macpherson's, it's not cognitive penetration if your belief that you have an important exam today causes light to flicker in your field of vision. Yet it might be, if your belief that there will be a thunderstorm today were to have the same effect.

Second, and following Dustin Stokes (2015), let us call a consequentialist about cognitive penetration someone who holds that the changes to perceptual content that result from cognition needn't be semantically coherent, but must instead have certain consequences. Which consequences? Stokes's preferred ones are given in the following, disjunctive definition:

$\psi$ is cognitive penetration if and only if $\psi$ is a cognitive-perceptual relation that implies consequences for theory-ladenness or the epistemic role of perception or mental architecture. (p. 92) ${ }^{12}$

The definition supplies a useful tool to test whether the cognitive penetrability of imagination counts as an instance of the cognitive penetrability of perception, as it should if perceptualism is true. From the consequentialist perspective: if perceptualism is true, then the cognitive penetrability of the imagination should have consequences for either the theory-ladenness of perception, or the epistemic role of perception or mental architecture.

Take first the theory-ladenness of perception. If perception is cognitively penetrable, then scientific observation risks being unable to adjudicate between rival theories. Rather, what the scientist sees, whether with the naked eye, through the telescope, or whatever, will simply reflect their prior theory. Thus, Jerry Fodor (1984) complains that the cognitive penetrability of perception will threaten the objectivity and theory-neutrality of perception.

The second consequence, the epistemic role of perception, is a generalisation of the first. If perception is cognitively penetrable, then what we (laypeople) see also risks being a function of what we expect or desire or believe we will see. Yet if

\footnotetext{
12 Compare Athanassios Raftopoulos (2017, np), another consequentialist: "whether some causal influence on perception counts as cognitive penetrability one should examine the effects of these influences."
} 
perception is to be of epistemic value at all, it must track the facts before us, not our prior beliefs/suspicions about those facts. Perception's key epistemic role is to correct false beliefs, but if it is cognitively penetrable by beliefs, then it will risk simply reinforcing these.

The third consequence, regarding mental architecture, concerns how perceptual systems and processing relate to cognitive systems and processing. Take vision. If visual experience is cognitively penetrable, then visual systems are not modular (Fodor, 1983); that is, they do not perform proprietary computations on input from the retina, preparing its 'raw data' for computations by distinct, domain general cognitive systems. On the modular view, the flow of information between sensory surfaces, visual systems and cognitive systems is a one-way street, with visual systems 'dumbly' offering up patterns of retinal information to thought. Contrastingly, if vision is cognitively penetrable, then the flow of information between visual and cognitive systems is a bidirectional exchange, with the former drawing on cognition as an informational resource when preparing the retina's raw data and sending it on to cognition.

As Stokes points out, the idea that perceptual states are cognitively penetrable is traditionally thought to have exactly these three consequences. Indeed, sceptics often rally against cognitive penetration because they find these consequences to be unpalatable or simply false. But saying that the imagination is cognitively penetrable seems not to have these consequences at all. This is further support for premise 5 of the Argument from Cognitive Penetration.

Take the first two consequences. Claiming that states of imagination are cognitively penetrable, i.e. that imagining an $F$ takes beliefs, memories, etc. about $F$ s as one of its inputs, does not threaten to rob us of our power to adjudicate between scientific theories via observation, nor can it rob perception of its more general epistemic cache. Given that the cognitive penetrability of the imagination is a seemingly unassailable fact, to hold otherwise would be to affirm that there is an in-principled conflict between the imagination and perception's epistemic functions. But the mere existence of imaginative states clearly does not have this as a consequence, even if, in highly-controlled experimental conditions, some perceptual states are mistaken for states of the imagination (Perky, 1910).

In terms of the third consequence, concerning mental architecture, the fact that states of the imagination are cognitively penetrable has no bearing on how visual systems handle retinal input. Whether the computations performed on raw, retinal data are proprietary to vision, or whether, in performing such computations, cognitive states are drawn on as informational resources, e.g., to resolve ambiguity, is not affected by the imagination being cognitively penetrated. States of the imagination can be as saturated with content from beliefs, desires, expectations, etc. as one's theory would like, and such architectural issues would remain entirely untouched.

Granted, the consequentialist perspective is just one way of thinking about cognitive penetration. Moreover, Stokes himself shies away from the idea that his disjunctive definition should be used to deliver verdicts on specific cases. So I don't take the lines of argument developed in this sub-section to be conclusive against perceptualism. (Indeed, as one can hopefully see, I take there to be multiple reasons to reject the view, so the case against it here is somewhat cumulative). But consequentialism 
does have certain strengths. Notably, and as Stokes points out, there are certain proffered cases of cognitive penetration in the literature, like the experiments conducted by Bruner and Goodman (1947), that only consequentialism, not semanticism, can accommodate for. Moreover, independent of the truth of consequentialism, it is plainly significant for the case against perceptualism that the cognitive penetrability of the imagination is neutral with respect to the key consequences alleged to follow from perception's penetrability, and which trouble sceptics so much. That this is so suggests that the cognitive penetrability of the imagination is not an instance of the cognitive penetrability of perception, independent of whether consequentialism is the correct account of the nature of cognitive penetration. This amounts to further support for premise 5 of The Argument from Cognitive Penetrability, thereby supporting the anti-perceptualist conclusion that imagination and perception are fundamentally distinct.

It might be argued that the two considerations I have offered in this paper against perceptualism are more fundamentally explained by the difference between perception and imagery being a causal one; the former is generated in a bottom-up, stimulus-driven manner while the latter is a matter of top-down processing (see Briscoe, 2011, pp. 164-165). Although I am sympathetic to this line of thought, I have hinted throughout that I believe this picture is too stark and doesn't hold in full generality. For one, there is evidence that attention penetrates visual experience itself, rather than operating pre- or post-perceptually (Mole, 2015; Stokes, 2018b). If this is correct, then perceiving is partially top-down. In the case of mental imagery, there is evidence that this can be triggered crossmodally, in a bottom-up, stimulus-driven manner that involves neither concepts nor cognition (Deroy \& Spence, 2013, p. 165). ${ }^{13}$

The more crucial matter, however, is conceptual: it must be remembered that the 'perceptual' in 'perceptualism' doesn't mean 'veridical perception' but 'perceptual experience'. So included here are non-veridical experiences, like illusion and hallucination. This makes all the difference. Indeed, as mentioned at the start of this paper, some perceptualists, like Nanay, take hallucination to be imagery's closest relative, and hallucinations are certainly not (if at all) triggered in a bottom-up manner. So, the claim that imagery and perception can be distinguished on the basis that imagery is (always? mostly?) a matter of top-down processing and perceptual experience is (always? mostly?) a matter of bottom-up processing would need to be severely qualified to make room for the perceptual experiences that imagery is claimed by some perceptualists to be most akin to. Qualifications made, I suspect that whatever residual, bottom-up/top-down differences remain (if any) will be insufficient to motivate a difference in kind rather than mere degree.

13 The fact that some mental imagery is cognitively penetrated doesn't mean all is. 


\section{The shared neural substrate argument}

So much for the two new arguments against perceptualism. But these can perhaps have only limited success in the overall case against perceptualism since they leave untouched what has recently emerged as the master argument for the view. Like the anti-perceptualist arguments developed above, this pro-perceptualist argument is one that could only have developed recently, certainly not during Hobbes's or Hume's time. But rather than being based on current trends in philosophy of mind and perception, this argument is based on a current trend in cognitive neuropsychology: research concerning the neural substrate of mental imagery.

For instance, in discussion of whether perception and imagination "have anything substantial in common or whether they are radically different", Bence Nanay (2016, p. 73) argues for the former on the grounds that neuropsychology has shown that visual perception and visual mental imagery share significant neural substrates:

[T]here is an almost complete overlap between the brain regions involved in perception and the brain regions involved in mental imagery, which suggests that the mental processes that make perception possible are the very same mental processes that make mental imagery possible. (Ibid.)

Likewise, Andy Clark, in his defence of the predictive processing approach to perception, claims that "perception and imagination are simply different ways of deploying the very same circuits and fundamental capacities." (2014, p. 39) Clark even goes so far as to claim that "imagery and perception are not simply activating overlapping neural areas but are actually deploying the very same finegrained internal representations when they do." (n. 16).

Alvin Goldman (2006, p. 43) is somewhat more cautious, admitting that we shouldn't expect imagery to share neural substrates with vision that are involved in organizing immediate sensory input. Nonetheless, Goldman claims, like Nanay and Clark, that his version of perceptualism is supported on neuropsychological grounds, citing "substantial similarity between the neural substrates of vision and visual imagery."

Strikingly, many studies by neuropsychologists report not just that mental imagery makes use of circuits in visual areas of the brain, but that it uses circuitry in V1 in particular (see Kosslyn et al. 2001, Pearson et al. 2015 and Dijkstra et al. 2019 for reviews). This is startling. V1 is the brain's primary visual cortex, the physical organisation of which is 'retinotopic' (Holmes, 1918; Horton \& Hoyt, 1991). This means that activation patterns in V1 preserve, with only minor spatial deformation, the patterns of stimulation observed at the retina. As a result, some have claimed that V1 is literally depictive of visual input, and that space on the visual cortex represents space in the world no less than the retina does (Kosslyn et al. 2006, p. 100). If the neural substrates of vision and mental imagery overlap so as to include V1, then this would seem considerable support for perceptualism.

Now, one way to push back would be to grant these empirical claims, but deny the inference from sameness of neural substrate to sameness of psychological 
kind. Peter Langland-Hassan (2015, p. 669) pursues this strategy, pointing out that the brain may use the same neural circuitry for functionally distinct tasks. Along similar lines, it has recently been argued in the neuroscience literature, apparently in direct contrast to Clark's remarks, that sameness of vision/imagery substrate fails to establish an identity of processing, since sameness of neural substrate is compatible with a difference in performed computation (Thorudottir et al. 2020).

But the claim that perception and imagery do, in fact, share neural substrates, at least as far as V1 is concerned, is one that we should not automatically grant. Although numerous philosophers follow Nanay, Clark and Goldman in claiming that neuropsychology has proven that V1 is among imagery's neural substrate, there are several controversies surrounding this matter which the philosophical literature has so far overlooked or ignored. Two recent meta-analyses of fMRI-based research on mental imagery are clear about how contentious the matter is. Far from championing V1 as a significant substrate of imagery, the first claims that research here is beset by "inconsistent findings and contested interpretations." (Winlove et al. 2018, p. 18) The other points to clinical findings "at odds with models [of imagery] proposing a crucial implication of early visual areas" (Spagna et al. 2021, p. 202) In closing, I will review some of the findings in this area in an attempt to defuse the shared neural substrate argument for perceptualism. To be clear: I won't be arguing that these findings show that V1 is definitely not part of imagery's neural substrate. Although I will be arguing that we have reason to take anti-V1 clinical results in this area more seriously than pro-V1 experimental results, the chief aim is simply to show the extent to which the shared neural substrate argument rests upon empirical premises that are highly disputed. ${ }^{14}$ As such, philosophers should be more cautious when advancing the argument.

\subsection{Inconsistent findings}

First, what are the inconsistent findings that Winlove et al. (2018) believe are present in the literature? Four are particularly striking. First, a number of experimental studies, almost half in their meta-analysis, reported that V1 was not active in imagerybased tasks, suggesting that V1 activation, although often present, is "not essential" (p. 18) for imagery. Second, Winlove and their collaborators found that V1 was only reliably activated in studies where subjects were instructed to close their eyes (p. 10 ). When neuroimaging studies on V1's role in imagery-generation were first performed, enforcing an eyes-closed condition was thought necessary to rule out that V1 circuitry was being activated by external stimuli. But the fact that this condition is correlated with increased activation of V1 circuitry, a result replicated elsewhere (Costumero et al. 2020), is puzzling. Indeed, when combined, these first two findings suggest that current neuropsychology remains somewhat in the dark about not

\footnotetext{
${ }^{14}$ By way of example, see the recent exchange in Nature Neuroscience between Bartolomeo et al. (2020) and Pearson (2020). My thanks to one of the journal's anonymous referees for drawing this to my attention.
} 
only V1's role in imagery generation, but also the nature of V1's functional connectivity more generally. Third, many early attempts to study imagery's neural substrate, and which were responsible for optimism about V1's necessity for imagery, relied on brain activity measures that would be considered "inappropriately lenient" (p. 8) by today's standards. ${ }^{15}$ Fourth, neuroimaging studies of V1 activity during imagery tasks often have small sample sizes (p. 7). As such, we should be cautious in inferring that any statistically significant result entails a real effect (see also Button et al. 2013); a small sample size entails that minor or even spurious variations between subjects will have a disproportionate influence on overall results.

\subsection{Clinical findings}

Winlove et al. are concerned by methodological difficulties in the experimental literature. But we might worry that they fail to pinpoint specific failings in this area. Spagna et al. (2021) approach the V1 controversy from a different angle. They are concerned to highlight observations of brain-damaged patients in clinical contexts that are "sharply discordant" (p. 202) with the experimental results yielded from the study of healthy, neurotypical subjects, and which supposedly show the necessity of V1 for imagery.

Spagna and colleagues call the view that V1 is a shared vision/imagery substrate the "dominant model," and note that it predicts the systematic co-occurrence vision/imagery deficits. The thought is this: if V1 is a shared vision/imagery substrate, then we should observe only coinciding vision/imagery impairments; there should not be observations of impaired imagery functions co-present with normal visual functions and vice versa. However, there is "extensive evidence" (p. 213) of vision/imagery double dissociations from observations of brain damaged patients, and which Spagna and colleagues use to argue that mental imagery "does not need activity in early visual areas." (Ibid.) (They ultimately argue that circuitry in the prefrontal cortex is the neural substrate of visual mental imagery, rather than areas in the occipital cortex, where V1 and related early visual areas are located.)

Two kinds of vision/imagery double dissociations found in the clinical literature bear on this discussion. Reflection on them can be used to flesh out the above claims by Spagna et al. (2021).

First, vision and visual imagery are doubly dissociable at a global, course-grained level. On the one hand, congenitally, totally blind individuals have been observed to be "well able" to perform visual imagery tasks (Aleman et al. 2001, p. 2603; see also Chatterjee \& Southwood 1995). On the other, aphantasic subjects, who lack mental imagery either congenitally or as a result brain damage, can have normal visual abilities. ${ }^{16}$ (Zeman et al. 2015).

\footnotetext{
15 Winlove and their collaborators do not specify which studies they have in mind. However, the most well-known early advocate of V1 as being part of imagery's neural substrate is Stephen Kosslyn, whose research is approvingly cited by Nanay (p. 67 and p. 73) and Goldman (p. 43).

16 It is sometimes claimed that aphantasics lack only voluntary imagery; this won't matter for my purposes.
} 
Cases of 'pure' aphantasia following brain damage, i.e. without other impairments, are rare. But examples do exist. For instance, one patient, described by Moro et al. (2008, p. 112), acquired aphantasia following brain damage and, despite being unable to imagine objects, was fully able to navigate their environment and visually identify objects, showing "no apparent impairments in their visual perceptual abilities." Thus Moro and their collaborators claim the case provides evidence of "a very clear dissociation" between vision and visual imagery.

A second patient with acquired aphantasia, R.M., reported by Farah et al. (1988), retained "good" (p. 161) visual object-recognition abilities, while being unable to imagine objects. ${ }^{17}$ Strikingly, both patients, through losing their capacity for mental imagery, exhibited what seem best described, from a philosophical perspective, as cognitive deficits rather than perceptual ones. The patient reported on by Moro and their collaborators had difficulty with practical reasoning, being unable to choose which snack to order when food was out of sight, but not, crucially, when placed before them (2008, p. 112). R.M. on the other hand had difficulty representing to themselves certain relational facts about types of objects, being unable to judge the truth value of so-called Eddy and Glass sentences (Eddy \& Glass, 1981). These are sentences thought to require imagery for verification, e.g., "A grapefruit is larger than an orange," in contrast with those that seemingly do not, and which R.M. was perfectly capable of verifying via semantic memory, e.g., "Animals are stuffed by a taxidermist." (p. 153).

The study of aphantasia is in its infancy, and several unresolved issues surround its connection to memory, dreaming and creativity (Dawes et al. 2020; Zeman et al. 2020; see also Whiteley forthcoming) But aphantasia's relevance for debates about the neural substrate of imagery is clear enough. As authors of one of the first, largescale studies of the condition put it:

[Aphantasia] suggests perception and imagery do not rely upon identical neural substrates and representations [and] acts as further evidence towards a growing body of work demonstrating key differences between imagery and perception. (Bainbridge et al. 2021, p. 160)

The shared neural substrate argument advanced by Nanay, Clark, Goldman and others, would thus seem to be severely undermined by the condition.

Second, and at a more domain-specific, fine-grained level, the following vision/ imagery dissociations have been observed in clinical contexts:

- impairment to colour imagery, despite normal colour perception (De Vreese, 1991),

- impairment to colour vision, despite normal colour imagery (Bartolomeo et al. 1997),

- impairment to the ability to identify words and numbers via imagery, but not perception (Bartolomeo et al. 1998); and

\footnotetext{
17 This was not, strictly speaking, a 'pure' case due to the patient's verbal alexia (p. 162), an inability to read whole words, and from which the clinicians inferred an attentional deficit.
} 
- impairment to the ability to identify words and numbers via perception, but not imagery (Sirigu \& Duhamel, 2001).

As one clinical review puts it, "every type of dissociation is possible" between vision and visual imagery (Bartolomeo, 2002, p. 372). This is not what should be observed, if V1 and other early visual areas of the brain are among the neural substrate of imagery.

It might be replied that these deficits are consistent with imagery and perception sharing a neural substrate. 'Perceptual' and 'imagistic' might simply be different ways of describing the same circuitry, bottom-up when perceptual and top-down when imagistic. What has gone wrong when, say, colour imagery is impaired, but colour perception is intact, might be that there is damage to top-down pathways that activate the substrate in question, with the bottom-up pathways remaining intact.

Something like the above may lurk in the back of Nanay's characterisation of mental imagery as "perceptual processing that is not triggered by corresponding sensory stimulation in a given sense modality." (2018, p. 127) Indeed, one can find neuropsychologists who defend the idea that imagery processing is just perceptual processing inverted (Dijkstra, 2020; see Pearson, 2019, pp. 625-626 for discussion). However, the idea that imagery processing is simply a 'reversed visual hierarchy' is controversial. Even Stephen Kosslyn and his collaborators, one of the chief champions of V1's role in imagery generation, seemingly walks back some of his claims in the face of clinical evidence of imagery/perception dissociations, cautioning against the view that imagery "is simply perception in the absence of immediate stimuli." (2006, p. 151) As Kosslyn notes, the sum total of the extant empirical literature, where this includes observations of brain-damaged patients, "paints a more complex picture."

Recently, Nanay (2021) has claimed that we should not necessarily think of aphantasics as lacking mental imagery (or lacking in the ability to intentionally generate mental imagery). This is because some aphantasics seem to lack only conscious imagery. Imagery may remain, just unconsciously. Why think this? Nanay points to a case of at least one aphantasic performing just as well as non-aphantasics on an imagery-related task, despite having no conscious imagery (Jacobs et al. 2018).

Now, construing aphantasia as a lack of conscious mental imagery, but with intact unconscious imagery, may offer the perceptualist a reply to the second line of objection developed above, i.e. which appealed to fine-grained imagery/perception dissociations. The reply might be that it has not been ruled out that the observed 'dissociation' of, e.g., colour imagery and colour vision, is not really a mere deficit of introspection; that is, what is lost in aphantasia is an inability to introspect a processing event as mental imagery while the ability to introspect it as perceptual experience remains intact. On this account, imagery and perception do not themselves dissociate, rather there is a problem of 'access' to what we can think of as one side of the imagery/perceptual processing coin.

This reply is not without its problems. For one, it still postulates a dissociation, only at the level of imagery/perception introspection rather than imagery/perception processing. This may not itself be problematic. However, the devil is in the details, 
since the reply requires substantial empirical assumptions about the ways that introspection can break down. In particular, an account is owed of how introspection can be neglectful in the relevant manner. How are introspective processes able to discern visual experience of colour, but not imagery experience of colour (or vice versa) though both are allegedly constituted by the same processing events?

Even with this issue solved, construing (at least some) cases of aphantasia as a mere loss of conscious imagery does not help with the first objection developed above. When the patients described by Moro et al. and Farah et al. lost mental imagery, what was thereby affected was nothing perceptual, but something wholly cognitive: practical reasoning (the patient who was indecisive about which snack to order) and difficulty forming beliefs about object types and their relational properties (R.M. performing an Eddy \& Glass sentence verification test). Understanding aphantasia as a loss of access to imagery does not speak to this objection to perceptualism. For the objection is that perceptualism gets wrong what kind of mental state or processing imagery is in the first place, never mind issues of consciousness versus unconsciousness (see also Cavedon-Taylor forthcoming).

In sum, current neuropsychology is equivocal at best on whether V1 is part of the neural substrate of mental imagery. In particular, one is liable to get a very different answer, depending on whether one asks an experimental or clinical neuropsychologist, even putting aside the inconsistencies in the experimental literature that Winlove et al. highlight.

I say that neuropsychology is equivocal here 'at best' because, ultimately, we have reason to take the anti-V1 clinical findings more seriously than the pro-V1 experimental findings. For what the experimental, i.e. brain-imaging, literature can reveal is only the correlation of brain activity with task performance. (In the case of MRI, this means the occurrence of blood-oxygen-level-dependent events.) Crucially, what this can't show is whether the circuits activated are directly causally responsible for that performance, even when neural activity is observed to go above a baseline resting state. For one, increased activity in V1 circuits during imagery tasks may be a result of the brain's suppressing visual activity, particularly in eyes-open conditions (Pylyshyn, 2002, p. 224; Fidelman, 1994). This would render increased activity in V1 during imagery tasks a mere enabling condition of imagery generation, rather than an activity in the brain that is directly causally relevant for imagery's instantiation. To investigate the locale of imagery's neutral substrate, understood as a true difference-maker rather than a mere enabling condition for that substrate (or simply an epiphenomenal concomitant or 'hanger-on'), we need dissociations rather than correlations. As Bartolomeo and colleagues recently put it:

Where does the discrepancy between the neuroimaging and [clinical] findings come from? The neuroimaging results supporting the hypothesis of an implication of early visual areas are correlative in nature, whereas deficits in people with brain injury demonstrate a causal contribution of the lesioned circuits to the relevant cognitive ability. (2020, p. 517)

The point is that what bears most directly on whether imagery shares a neural substrate with vision and visual experience is whether there are dissociations between the two, and not, crucially, whether they are co-present in healthy subjects. 
Why is that? An analogy might be instructive: the fact minds are observed, in actuality, to be correlated with brains is neither here nor there for whether mind-body dualism is true. For what bears on the question of dualism is whether mind and brain can dissociate (as a matter of metaphysical possibility). The question is not whether there is, in actual fact, a separation, but whether the two are separable. Likewise, the observed correlation of $\mathrm{V} 1$ activity with performance on imagery tasks in brain imaging studies does not settle V1's necessity for mental imagery. Like the question of mind-body dualism, the question of whether V1 is a part of imagery's neural substrate also boils down to whether a kind of separation is possible (albeit, in this case, nomologically). Clinical neuropsychology, and in particular the study of aphantasia, supplies evidence that it is.

Acknowledgements My thanks to two of the journal's anonymous referees.

Open Access This article is licensed under a Creative Commons Attribution 4.0 International License, which permits use, sharing, adaptation, distribution and reproduction in any medium or format, as long as you give appropriate credit to the original author(s) and the source, provide a link to the Creative Commons licence, and indicate if changes were made. The images or other third party material in this article are included in the article's Creative Commons licence, unless indicated otherwise in a credit line to the material. If material is not included in the article's Creative Commons licence and your intended use is not permitted by statutory regulation or exceeds the permitted use, you will need to obtain permission directly from the copyright holder. To view a copy of this licence, visit http://creativecommons.org/licen ses/by/4.0/.

\section{References}

Aleman, A., van Lee, L., Mantione, M., Verkoijen, I., \& de Haan, E. (2001). Visual imagery without visual experience: Evidence from congenitally totally blind people". NeuroReport, 12, 2601-2604.

Allen, K. (2015). Hallucination and imagination. Australasian Journal of Philosophy, 93, 287-302.

Anderson, E., \& Barrett, L. (2016). Affective beliefs influence the experience of eating meat. PLoS ONE, 11, e0160424.

Bainbridge, W., Pounder, Z., Eardley, A., \& Baker, C. (2021). Quantifying aphantasia through drawing: Those without visual imagery show deficits in object but not spatial memory. Cortex, 135, $159-177$.

Bartolomeo, P. (2002). The relationship between visual perception and visual mental imagery: A reappraisal of the neuropsychological evidence. Cortex, 38, 357-378.

Bartolomeo, P., Bachoud-Levi, A., De Gelder, B., Denes, G., Dalla Barba, G., Brugieres, P., \& Degos, J. (1998). Multiple-domain dissociation between impaired visual perception and preserved mental imagery in a patient with bilateral extrastriate lesions. Neuropsychologia, 36, 239-249.

Bartolomeo, P., Bachoud-Levi, A., \& Denes, G. (1997). Preserved imagery for colours in a patient with cerebral achromatopsia". Cortex, 33, 369-378.

Bartolomeo, P., Hajhajate, D., \& Liu., J. \& Spagna, A. . (2020). Assessing the causal role of early visual areas in visual mental imagery. Nature Reviews Neuroscience, 21, 517.

Bayne, T. (2009). Perception and the reach of phenomenal content. The Philosophical Quarterly, 59, $385-404$.

Beck, J. (2018). Marking the perception-cognition boundary: The criterion of stimulus-dependence. Australasian Journal of Philosophy, 96, 319-334.

Block, N. (2014). Seeing-as in the light of vision science. Philosophy and Phenomenological Research, $89,560-572$.

Block, N. (2016). Tweaking the concepts of perception and cognition. Behavioral and Brain Sciences, 39, 21-22. 
Briscoe, R. (2011). Mental imagery and the varieties of amodal perception. Pacific Philosophical Quarterly, 92, 153-173.

Brogaard, B. (2016). Perceptual appearances of personality. Philosophical Topics, 44, 83-103.

Bruner, J., \& Goodman, C. (1947). Value and need as organizing factors in perception. Journal of Abnormal Psychology, 2, 33-44.

Button, K., Ioannidis, J., Mokrysz, C., Nosek, B., Flint, J., \& Robinson, E. (2013). Power failure: Why small sample size undermines the reliability of neuroscience. Nature Reviews Neuroscience, 14, $365-376$.

Byrne, A. (2007). Possibility and imagination. Philosophical Perspectives, 21, 125-144.

Byrne, A. (2009). Experience and content. The Philosophical Quarterly, 59, 429-451.

Byrne, A. (2016). Rich or thin? In Nanay (Ed.), Current controversies in philosophy of perception. Routledge.

Cavedon-Taylor, D. (2021). High-level perception and multimodal perception. In H. Logue \& L. Richardson (Eds.), Purpose and procedure in philosophy of perception. OUP.

Cavedon-Taylor, D. (forthcoming). "Mental imagery: Pulling the plug on perceptualism." Philosophical Studies.

Chatterjee, A., \& Southwood, M. H. (1995). Cortical blindness and visual mental imagery. Neurology, 45, 2189-2195.

Clark, A. (2014). Perceiving as predicting. In D. Stokes, M. Matthen, \& S. Biggs (Eds.), Perception and its modalities. OUP.

Costumero, V., Bueichekú, E., Adrián-Ventura, J., \& Ávila, C. (2020). Opening or closing eyes at rest modulates the functional connectivity of V1 with default and salience networks. Scientific Reports, $10,9137$.

Dawes, A., Keogh, R., Andrillon, T., \& Pearson, J. (2020). A cognitive profile of multi-sensory imagery, memory and dreaming in aphantasia. Scientific Reports, 10, 10022.

De Vreese, L. (1991). Two systems for colour-naming defects: Verbal disconnection vs colour imagery disorder. Neuropsychologia, 29, 1-18.

Dijkstra, N., Bosch, S., \& van Gerven, M. (2019). Shared neural mechanisms of visual perception and imagery. Trends in Cognitive Sciences, 23, 423-434.

Dijkstra, N., Ambrogioni, L., Vidaurre, D., \& van Gerven, M. (2020). Neural dynamics of perceptual inference and its reversal during imagery. eLife. https://doi.org/10.7554/eLife.53588

Dorsch, F. (2016). Hume. In Kind (Ed.), The routledge handbook of philosophy of imagination. Routledge.

Dretske, F. (1995). Naturalizing the mind. MIT Press.

Eddy, J. K., \& Glass, A. L. (1981). Reading and listening to high and low imagery sentences. Journal of Verbal Learning and Verbal Behavior, 20, 333-345.

Farennikova, A. (2013). Seeing absence. Philosophical Studies, 66, 429-454.

Farah, M. J., Levine, D. N., \& Calvanio, R. (1988). A case study of mental imagery deficit. Brain and Cognition, 8, 147-164.

Fidelman, U. (1994). A misleading implication of the metabolism scans of the brain. International Journal of Neuroscience, 74, 105-108.

Firestone, C., \& Scholl, B. (2016). Cognition does not affect perception: Evaluating the evidence for "topdown" effects. Behavioral and Brain Sciences, 39, 1-72.

Fish, B. (2013). High-level properties and visual experience. Philosophical Studies, 162, 43-55.

Fodor, J. (1983). The modularity of mind. MIT Press.

Fodor, J. (1984). Observation reconsidered. Philosophy of Science, 51, 23-43.

Goldman, A. (2006). Imagination and simulation in audience responses to fiction. In Nichols (Ed.), The architecture of the imagination. OUP.

Gregory, D. (2013). Showing sensing and seeming. OUP.

Hobbes, T. (1651/1991). Leviathan. CUP.

Holmes, G. (1918). Disturbances of vision by cerebral lesions. British Journal of Ophthalmology, 2, 353.

Horton, J., \& Hoyt, W. (1991). The Representation of the visual field in human striate cortex. A revision of the classsicholmes map. Archives of Ophthalmology, 109, 816-824.

Howe, P., \& Carter, O. (2016). Hallucinations and mental imagery demonstrate top-down effects on visual perception. Behavioral and Brain Sciences, 39, 37-38.

Hume, D. (1739/2000). A treatise of human nature. OUP.

Jacobs, C., Schwarzkopf, D., \& Silvano, J. (2018). Visual working memory performance in aphantasia. Cortex, 105, 61-73. 
Kind, A. (2020). Imaginative experience. In Kriegel (Ed.), The Oxford handbook of the philosophy of consciousness. OUP.

Kosslyn, S., Ganis, G., \& Thompson, W. (2001). Neural foundations of imagery. Nature Reviews Neuroscience, 2, 635-642.

Kosslyn, S., Thompson, W., \& Ganis, W. (2006). The case for mental imagery. OUP.

Kriegel, U. (2015). Perception and imagination: A sartrean account. In S. Miguens, G. Preyer, \& C. B. Morando (Eds.), Pre-reflective consciousness: Sartre and contemporary philosophy of mind. Routledge.

Kung, P. (2010). Imagining as a guide to possibility. Philosophy and Phenomenological Research, 81, 620-663.

Langland-Hassan, P. (2015). Imaginative attitudes. Philosophy and Phenomenological Research, 90, $665-686$.

Liao, S-Y., \& Gendler, T. (2019). “Imagination.” In Zalta, E. (ed.) Stanford encyclopedia of philosophy. URL $=$ https://plato.stanford.edu/archives/win2019/entries/imagination/.

Logue, H. (2013). Visual experience of natural kind properties: Is there a fact of the matter? Philosophical Studies, 162, 1-12.

Machery, E. (2015). Cognitive penetrability: A no-progress report. In A. Raftopoulos \& J. Zeimbekis (Eds.), The cognitive penetrability of perception. OUP.

Macpherson, F. (2012). Cognitive penetration of colour experience: Rethinking the issue in light of an indirect mechanism. Philosophy and Phenomenological Research, 84, 24-62.

Martin, M. G. F. (2002). The transparency of experience. Mind \& Language, 17, 376-425.

Matey, J. (2014). Can blue mean four? In D. Bennett \& C. Hill (Eds.), Sensory integration and the unity of consciousness. MIT Press.

Mole, C. (2015). Attention and cognitive penetration. In A. Raftopoulos \& J. Zeimbekis (Eds.), The cognitive penetrability of perception. OUP.

Moro, V., Berlucchi, G., Lerch, J., Tomaiuolo, F., \& Aglioti, S. (2008). Selective deficit of mental visual imagery with intact primary visual cortex and visual perception. Cortex, 44, 109-118.

Nanay, B. (2011). Do we see apples as edible? Pacific Philosophical Quarterly, 92, 305-322.

Nanay, B. (2015). Perceptual content and the content of mental imagery. Philosophical Studies, 172, $1723-1736$.

Nanay, B. (2016). Hallucination as mental imagery. Journal of Consciousness Studies, 23, 65-81.

Nanay, B. (2017). Pain and mental imagery. The Monist, 100, 485-500.

Nanay, B. (2018). Multimodal mental imagery. Cortex, 105, 125-134.

Nanay, B. (2020). Multimodal mental imagery and perceptual justification. In D. Gatzia \& B. Brogaard (Eds.), The epistemology of non-visual perception. OUP.

Nanay, B. (2021). Unconscious mental imagery. Philosophical Transactions of the Royal Society B, 376, 20190689.

Noordhoff, P. (2002). Imagining objects and imagining experiences. Mind \& Language, 17, 426-455.

Peacocke, C. (1985). Imagination, experience, and possibility. In J. Foster \& H. Robinson (Eds.), Essays on berkeley. OUP.

Peacocke, C. (1992). A study of concepts. MIT Press.

Pearson, J., Naselaris, T., Holmes, E. A., \& Kosslyn, S. (2015). Mental imagery: Functional mechanisms and clinical applications. Trends in Cognitive Sciences, 19, 590-602.

Pearson, J. (2019). The human imagination: The cognitive neuroscience of visual mental imagery. Nature Reviews Neuroscience, 20, 624-634.

Pearson, J. (2020). Reply to: Assessing the causal role of early visual areas in visual mental imagery. Nature Reviews Neuroscience, 21, 517.

Perky, C. W. (1910). An experimental study of imagination. American Journal of Psychology, 21, $422-452$.

Prinz, J. (2006). Is the mind really modular? In R. Stainton (Ed.), Contemporary debates in cognitive science. Blackwell.

Phillips, B. (2019). The shifting border between perception and cognition. Nous, 53, 316-346.

Price, R. (2009). Aspect-switching and visual phenomenal character. The Philosophical Quarterly, 59, $508-518$.

Pylyshyn, Z. (1999). Is vision continuous with cognition? The case for cognitive impenetrability of visual perception. Behavioral and Brain Sciences, 22, 341-423.

Pylyshyn, Z. (2002). Mental imagery. In search of a theory. Behavioral and Brain Sciences, 25, 157-238. 
Raftopoulos, A. (2009). Cognition and perception: How do psychology and neural science inform philosophy? MIT Press.

Raftopoulos, A. (2017). Pre-cueing, the epistemic role of early vision, and the cognitive impenetrability of early vision. Frontiers in Psychology, 8, 1156.

Reiland, I. (2014). On experiencing high-level properties. American Philosophical Quarterly, 51, $177-187$.

Sartre, J-P. (1940/1972). The psychology of the imagination. Routledge.

Siegel, S. (2006). Which properties are represented in perception? In T. Gendler \& J. Hawthorne (Eds.), Perceptual experience. OUP.

Siegel, A., \& Silins, N. (2015). The epistemology of perception. In M. Matthen (Ed.), Oxford handbook to the philosophy of perception. OUP.

Sirigu, A., \& Duhamel, J. (2001). Motor and visual imagery as two complementary but neurally dissociable mental processes. Journal of Cognitive Neuroscience, 13, 910-919.

Soteriou, M. (2013). The mind's construction. OUP.

Spagna, A., Hajhajate, D., Liu, J., \& Bartolomeo, P. (2021). Visual mental imagery engages the left fusiform gyrus, but not the early visual cortex: A meta-analysis of neuroimaging evidence. Neuroscience \& Biobehavioral Reviews, 122, 201-217.

Spence, C., \& Deroy, O. (2013). Crossmodal mental imagery. In S. Lawson \& R. Lacey (Eds.), Multisensory imagery. Springer.

Stock, K. (ms.) "Mental images are not interestingly multifunctional."

Stokes, D. (2015). Towards a consequentialist understanding of cognitive penetration. In A. Raftopoulos \& J. Zeimbekis (Eds.), The cognitive penetrability of perception. OUP.

Stokes, D. (2018a). Rich perceptual content and aesthetic properties. In A. Bergqvist \& R. Cowan (Eds.), Evaluative perception. OUP.

Stokes, D. (2018b). Attention and the cognitive penetrability of perception. Australasian Journal of Philosophy, 96, 303-318.

Thorudottir, E., Sigurdardottir, H., Rice, G., Kerry, S., Robotham, R., Leff, A., \& Starrfelt, R. (2020). The architect who lost the ability to imagine: The cerebral basis of visual imagery. Brain Sciences, 10, 59.

Tye, M. (1995). Ten problems of consciousness. MIT Press.

Whiteley, C. (forthcoming). "Aphantasia, imagination and dreaming." Philosophical Studies.

Wiltsher, N. (2016). Against the additive view of the imagination. Australasian Journal of Philosophy, 94, 266-282.

Winlove, C., Milton, F., Ranson, R., Fulford, J., MacKisack, M., Macpherson, F., \& Zeman, A. (2018). The neural correlates of visual imagery: A co-ordinate-based meta-analysis. Cortex, 105, 4-25.

Wittgenstein, L. W. (1948/1980). Remarks on the philosophy of psychology, Vol. II. University of Chicago Press.

Young, B. (2020). Olfactory imagery: Is exactly what it smells like. Philosophical Studies, 177, 3303-3327.

Zeimbekis, J. (2015). Seeing, visualizing and believing. In A. Raftopoulos \& J. Zeimbekis (Eds.), The cognitive penetrability of perception. OUP.

Zeman, A., Dewar, M., \& Della Sala, S. (2015). Lives without imagery: Congenital aphantasia. Cortex, 73, 378-380.

Zeman, A., Milton, F., Della Sala, S., Dewar, M., Frayling, T., Gaddum, J., Hattersley, A., HeuermanWilliamson, B., Jones, K., MacKisack, M., \& Winlove, C. (2020). Phantasia-the psychological significance of lifelong visual imagery vividness extremes. Cortex, 130, 426-440.

Publisher's Note Springer Nature remains neutral with regard to jurisdictional claims in published maps and institutional affiliations. 